\title{
Remote Compression Test Machine for Experimental Teaching of Mechanical Forming
}

\author{
http://dx.doi.org/10.3991/ijoe.v12i04.5085 \\ L. B. Michels ${ }^{1}$, L. Schaeffer ${ }^{3}$, V. Gruber ${ }^{2}$, R. Marcelino ${ }^{2}$, Luan C. Casagrande ${ }^{2}$ \\ ${ }^{1}$ Instituto Federal de Santa Catarina, Araranguá, Brazil \\ ${ }^{2}$ Universidade Federal de Santa Catarina, Araranguá \\ ${ }^{3}$ Universidade Federal do Rio Grande do Sul, Porto Alegre
}

\begin{abstract}
There are many remote experiments currently being created, but just few of these remote experiments are from the field of metallurgical engineering. The purpose of this article is to describe the development of the remote compression test machine. This experiment is an educational experiment aimed to conduct a compression test via the internet. It uses the microcomputer Raspberry $\mathrm{Pi}$ as the main data control. This remote experiment is available in a website, where the students can control and monitor it and export the output data. The tests realized in the remote compression test machine demonstrated that the output is similar to industrial machine allowing its use as a didactic experiment.
\end{abstract}

Index Terms-Remote Experiment, Compression Test, Metallurgical Engineering, Educational Experiment, Raspberry $\mathbf{P i}$.

\section{INTRODUCTION}

Mechanical Conformation is one of the main areas in Metallurgical Engineering. Compression tests are part of the basic knowledge for understanding of metal forming theory. These tests are a way of understand the behavior of a metal in a deformation process and thus extract important parameters for designing formed parts.

Mainly in engineering and experimental sciences, the experimentation is essential in the learning process $[1,2]$. Without interaction, students are passive and the learning process is slow [3]. However, in general, resources are not available to develop these objectives mainly because of the high cost [4]. Besides being expensive, this kind of machine is dangerous, and as a consequence, it creates the necessity of a qualified professional to guide students during the conformation process in order to reduce risks of accidents or damage to the machine.

With the goal to extend the experimentation in schools and universities, new solutions have been created through advances in Information and Communication Technology [5]. One of these most promising advances is called remote experiment [6]. Such experiments can be used to represent a laboratory to provide interaction and observation of practical phenomena through experiments, aiming to facilitate theoretical learning. The main advantages of the remote experiments are the availability of access without a technical support and risks of accidents or damage to the machine. Because of this, the use of online educational remote experiments is very important for engineering students [2].
However, in the area of metallurgical engineering, the number of remote experiments being developed is small mainly because of the high cost to develop a remote machine, and the necessity of regular maintenance.

The objective of this article is to demonstrate the development of an educational experiment called Educational Remote Compression Test Machine. This experiment was created and developed in Brasil by LABTEL laboratory from Universidade Federal de Santa Catarina in a partnership with researchers from Universidade Federal do Rio Grande do Sul and Instituto Federal de Santa Catarina.

The objective of the Educational Remote Compression Test Machine is to execute a remote compression test using as sample mini specimens made from aluminum.

\section{EXPERIMENT MAIN STRUCTURE}

The experiment is composed by the following components: (Items "a", "b", "c" e "d"), and a webpage (item "h") and these two parties are interconnected via the Internet " $g$ " as show in Error! Reference source not found. The item "f" of this figure indicates that the user will have access to the website and the experiment through the internet. In the subchapters below is detailed the items described above and in the Figure 1.

\section{A. Compression Testing Machine}

This component is a mechanical structure that is responsible for the processes of compression of the specimen through the force of a hydraulic cylinder (Figure 1). This is the main component of the experiment because this is the place where occurs the phenomenon under study. The machine has two different sensors that are responsible to measure force and displacement. These sensors are fundamental for the experiment because they will register the behavior of the mechanical test specimen during the experimentation process. In addition, they will provide the necessary data that is essential for the construction of the flow curve of the metal.

Data Processing Panel Educational Compression Testing The microcomputer will control the streaming of video through a webcam. The replacement of specimen will be realized by a low cost system with a step motor that will create a linear movement of advancement and return.

\section{B. Hydraulic Unit;}

The Hydraulic unit and the pumping oil system are responsible to generate the necessary flow of oil to the hydraulic cylinder. 

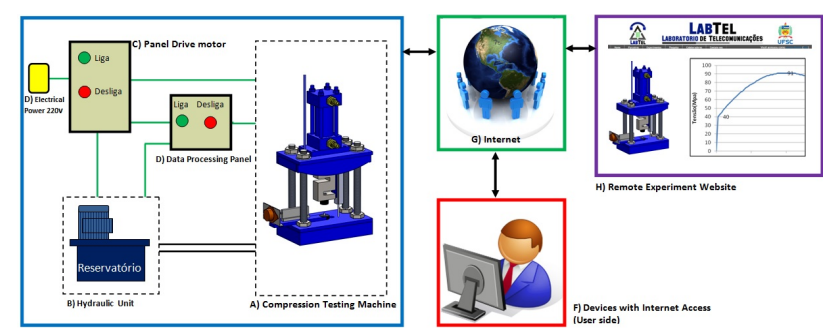

Figure 1. General Vision
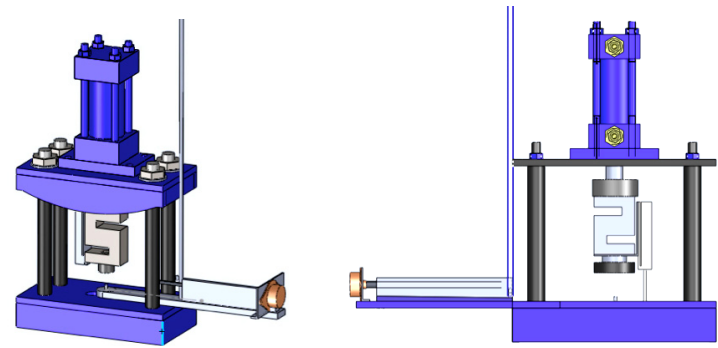

Figure 2. Machine Tele Operated

\section{Motor Drive Panel;}

The motor drive panel is a fundamental part to start the pump of the hydraulic unit. This panel has a frequency inverter to control the motor start and the voltage conversion from $220 \mathrm{~V}$ to $380 \mathrm{~V}$.

\section{Data Processing Panel;}

The data processing panel (Figure 3) has a component called Raspberry Pi.

Raspberry Pi is a modern, small and low cost microcomputer that additionally to all the computer functions can do the data acquisition, control and signal processing [7].

This equipment is responsible for the data acquisition from the sensors, to stream the video from the webcam, to control the relays, motor and the lamps, and to control the communication between the user and the machine through the network. Through the Raspberry Pi, the remote compression test machine is connected to the internet, and as a consequence, it is possible to observe and control the machine through the website.

\section{E. Electrical Power}

Electrical power must be 220 volts to charge all the circuits in the control panel and others circuits.

\section{F. Devices with Internet Access;}

All the devices with network access will have access to the experiment. Consequently, the user will be able to access the experiment from everywhere with network access at any time.

\section{G. Internet Access;}

Internet is responsible to allow the interface between the microcomputer and the users.

\section{H. Remote Experiment Website}

The website (Figure 4) will provide the control and monitoring of the experiment in real time. The web page was developed using the learning management system MOODLE. This important tool created the possibility to

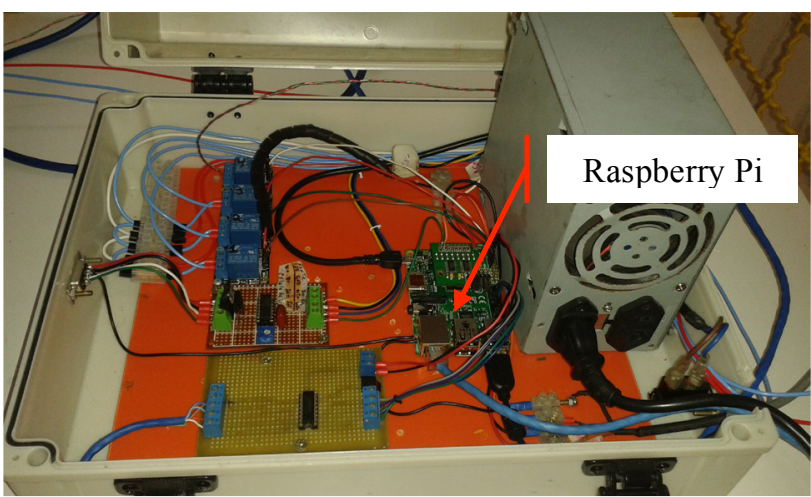

Figure 3. Data Processing Panel

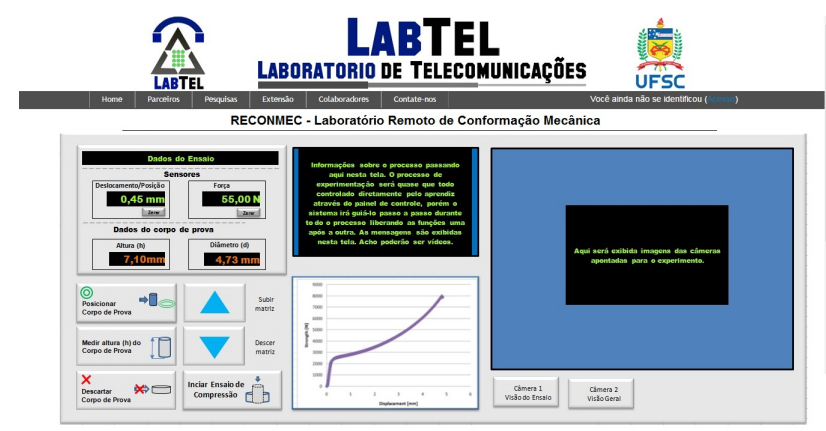

Figure 4. Website

export the data from the experimentation process and to explain material about this experiment and the flow curves.

The control panel present in the website is composed by 3 (three) main windows. The first one displays the live streaming of video of the experimentation process. The other window is being used to inform about the step-bystep process of the experimentation, as well as the actual status of the process. The third window displays the chart with data from the force $(F)$ and the height delta of the specimen in real time.

\section{EXPERIMENTATION PROCESS}

In the beginning of the process, the user will need to access the Web Site www.labtel.com.br and choose the option Educational Remote Compression Testing Machine. In this new environment, the student will be able to start the experimentation process and he/she will be guided step-by-step in each stage. During this performance, the webcam will show the low cost system positioning the specimen, the compression, and finally the discard of the specimen. Finally, the user will be able to get all the output data and to use spreadsheets in the Web page to calculate and to create a chart tension versus deformation.

The dimensions of the specimen are given in the beginning of the experiment. Before creating the chart, the learner can watch instructional videos and read texts about the subject.

A summary of the experimentation process can be seen in Figure 5.

\section{TEST OF EXPERIMENT}

With the aim of testing the repeatability of the remote experiment, 4 (four) conformation tests were performed. The outputs from these tests were compared with 4 (four) conformation tests that were performed in an industrial 
compression test machine EMIC. 4 (four) charts were plotted in Figure 6, wherein 2 of these charts are from the educational machine and the other 2 are from the industrial machine (EMIC). These 4 charts were chosen randomly to reduce the amount of information in the final image.

It is possible to conclude from the Figure 6 that the output data presented repeatability. This is another very important criterion to ensure that each test will display the same phenomena planned for the experiment.

Considering these analyzes, it is possible to conclude that the Educational Compression Test Machine can be used for teaching purposes as designed.

\section{CONCLUSION}

The Educational Remote Compression Test Machine is a success for the experimentation field, because the output data showed repeatability and characteristics of an industrial machine, and as a consequence, it can be used in the learning process as an educational remote experiment. These results are important to expand knowledge in the teaching are of metal forming, as well as for further research on remote labs.

Despite the difficulties in creation of remote laboratories and experiments in the mechanical forming area, it is essential to invest more and deepen more in this research field.

\section{REFERENCES}

[1] A. Ikhlef, M. Kihel, B. Boukhezzar, A. Guerrouj and N. Mansouri, "Online Temperature Control System," in International Conference on Interactive Mobile Communication Technologies and Learning (IMCL), 2014. http://dx.doi.org/10.1109/imctl. $\underline{2014.7011108}$

[2] F. H. Villa-López, J. García-Guzmán, J. V. Enríquez, S. LealOrtíz and A. Ramírez-Ramírez, "Electropenumátic system for industrial automation: Remote experiment within a web-based learning environment," Procedia Technology, vol. 7, pp. 198-207, 2013. http://dx.doi.org/10.1016/j.protcy.2013.04.025

[3] E. Fabregas, G. Farias, S. Dormido-Canto, S. Dormido and F. Esquembre, "Development a remote laboratory for engineering education," Computers \& Education, vol. 57, 2011.

[4] Y. Khazri, M. Rouane, A. Fahli, M. Moussetad, A. Khaldouni and A. Naddami, "Developing a Remote Practice for Laboratory Experiments on Measuring Instruments," IJOE, vol. 10, no. 5, 2014.

[5] M. G. Valls and P. B. Val, "Usage of DDS Data-Centric Middleware for Remote Monitoring and Control Laboratories," IEEE IEEE Transactions On Industrial Informatic, vol. 9, no. 1, pp. 567-574, Fevereiro 2013. http://dx.doi.org/10.1109/ TII.2012.2211028

[6] D. Lowe, "Integrating Reservations and Queuing in Remote Laboratory Scheduling," IEEE TRANSACTIONS ON LEARNING TECHNOLOGIES, vol. 6, no. 1, pp. 73-84, Janeiro-Março 2013. http://dx.doi.org/10.1109/TLT.2013.5

[7] S. Goodwin, Smart Home automation with Linux and Raspberry, 2 ed., 2013.

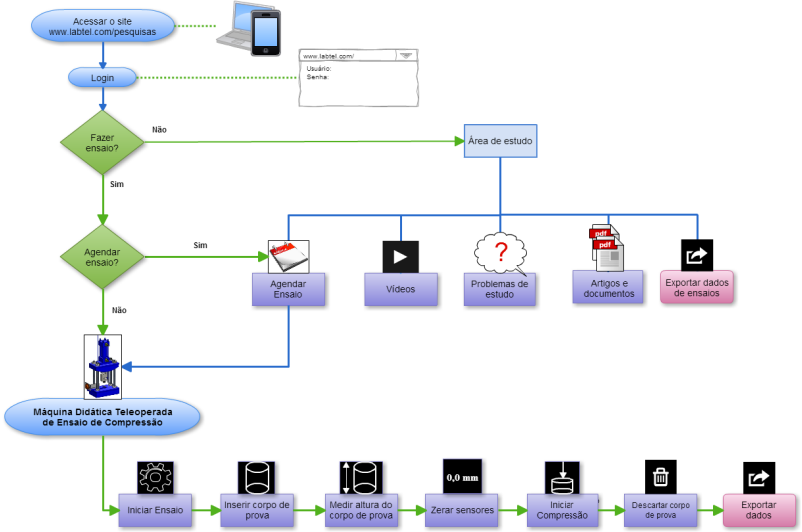

Figure 5. Flow Chart from experimentation process in the website

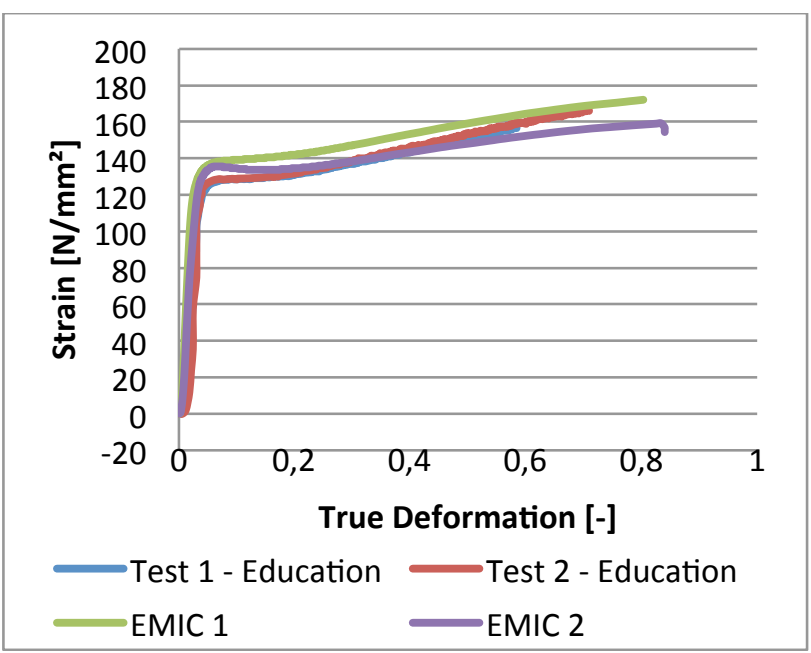

Figure 6. Output from Educational Machine $\mathrm{x}$ Industrial Machine (EMIC)

\section{AUTHORS}

L. B. Michels is with the Federal Institute of Santa Catarina, Araranguá, Brazil (e-mail: lucasboeiramichels@gmail.com).

L. C. Casagrande is with Federal University of Santa Catarina, Araranguá, Brazil. (e-mail: luanccasagrande@gmail.com.

V. Gruber is with Federal University of Santa Catarina, Araranguá, Brazil (e-mail: vilson.gruber@ufsc.br,

R. Marcelino is with Federal University of Santa Catarina, Araranguá, Brazil (e-mail: roderval.marcelino@ufsc.br,

L. Schaeffer is with Federal University of Rio Grande do Sul, Porto Alegre, Brazil (e-mail: schaefer@ufrgs.br.

Submitted 28 September 2015. Published as resubmitted by the authors 16 December 2015. 